\title{
Os historiadores e seus públicos: desafios ao conhecimento histórico na era digital ${ }^{1}$
}

Historians and their audiences: Challenges to historical knowledge in the digital age

Jurandir Malerba*

\section{RESUmo}

A quebra da autoridade do historiador acadêmico sobre a produção do conhecimento histórico no contexto da difusão das mídias digitais é o centro da reflexão aqui proposta. Parte-se da consideração da historicidade dos sujeitos da produção e do consumo da história, passando aos desafios lançados pela difusão exponencial da história possibilitada pela internet, para se chegar à discussão da função social do historiador acadêmico hoje.

Palavras-chave: Historiografia; história pública; mídias digitais.

\begin{abstract}
The breakdown of academic historians' authority over the production of historical knowledge in the context of digital media dissemination is the axis of reflection here unfolded. It starts from the consideration of the historicity of the subject of production and consumption of history, then moving on to the challenges posed by the exponential spread of history made possible by the internet, to get to the discussion of the social function of the academic historian today.

Keywords: Historiography; public history; digital media.
\end{abstract}

Em evento recente, ao procurar responder à questão de ¿por qué y para quién escribimos?, a historiadora colombiana Marixa Lasso lançava, em chave dramática, uma questão atual: a do enterro da profissão de historiador tal como a conhecemos. Sentenciava, então, que "la profesión que hemos conocido durante los últimos 50 o 70 años, la profesión en la que me formé, y en la que todos nos formamos esta desapareciendo". Para desenvolver sua afirmação, a catedrática da Universidad Nacional de Colombia lança uma anedota: a pergunta que lhe fez um famoso historiador seu amigo: “ ¿por qué estas escribiendo un libro, si con el esfuerzo que lleva escribir un libro puedes escribir cuatro

\footnotetext{
* Instituto de Filosofia e Ciências Humanas (IFCH), Universidade Federal do Rio Grande do Sul (UFRGS). Porto Alegre, RS, Brasil. jurandirmalerba1@gmail.com ${ }^{2}$
} 
artículos que te van a dar tres o cuatro veces el puntaje académico y salarial?". Sua resposta conduziu-a a outras questões, candentes no tempo presente e igualmente pertinentes ao cenário acadêmico brasileiro: "en que formato escribimos (libro o articulo especializado) y en qué idioma escribimos (inglés o español). Lo que lleva a una pregunta aún mas importante ... ¿por qué escribimos y para quién escribimos?" (Lasso, 2016).

Na construção de seu argumento, Lasso abre para uma autocrítica que em geral, talvez por imperativos corporativos, os historiadores evitamos encarar, que é a de nosso afastamento do grande público. Desde sua institucionalização universitária com a inauguração da primeira cátedra por Leopold von Ranke em Berlim em 1825, mas principalmente ao longo do século XX, a profissionalização da história procurou identificar-se a um cânone científico, ${ }^{3}$ uma história próxima dos métodos de outras ciências sociais, menos anedótica e mais analítica, como a sociologia e a antropologia. Uma história que procurava evitar o anacronismo e utilizar de maneira séria e profunda o método crítico e os documentos dos arquivos. No esforço de se fazer da história uma ciência social, porém, perdemos muito da nossa ligação com a literatura, começamos a escrever numa linguagem técnica, para pares, e nos afastamos do grande público (Lasso, 2016).

Sem mais avançar no desenvolvimento de seu argumento, o introito de Marixa Lasso serve de pretexto para nossa aproximação ao objeto da relação entre "o historiador e seus públicos hoje". O melhor equacionamento desse problema, parece-nos, exige a consideração de três conjuntos de questões, que dão corpo às três seções constituintes deste artigo. Num primeiro momento, a relação historiador/historiografia/público há de se ser colocada em perspectiva histórica, no sentido de que tanto os sujeitos desse tripé quanto os meios (as mídias) de sua conexão variaram em cada tempo/espaço considerado. Em segundo lugar, no contexto dessa relação nos dias atuais, o advento dos meios digitais, nomeadamente a internet, alterou dramaticamente os elementos constituintes do trinômio. Por fim, neste quadrante, em que a prática historiadora extravasa para além dos circuitos institucionais tradicionais de tal modo a se questionar o próprio sentido da história como disciplina acadêmica, a reflexão sobre o papel social do historiador profissional impõe-se com fragorosa urgência.

\section{QUEM ESCREVE HISTÓRIA?}

Um bom arranjo das dúvidas relativas à questão do historiador e suas audiências hoje talvez seja a consideração do "círculo semiótico", ${ }^{4}$ embora o 
desenvolvimento de meu argumento não se enrede propriamente por ele: a relação entre emissor-mensagem-receptor, ou entre historiador-escrita histórica/historiografia-público. As questões que emanam dessa propositura são potencialmente infinitas e reclamam a definição de um caminho. O primeiro item do tripé abre para questões de ordem ética, em torno da(s) responsabilidade(s) do(a) historiador(a). Mas quem é o historiador, hoje? O profissional acadêmico treinado na universidade cada vez mais especializado que escreve para os pares em revistas indexadas e ranqueadas, o diletante amador que escreve em seu blog, ou o escritor leigo de história e autor de best-seller? A depender da resposta a essa questão, variará o que podemos e devemos entender pelo segundo item do tripé: o que é historiografia, qual historiografia? Assim também para o que entendemos por "público": os historiadores, leitores de nós mesmos, o internauta curioso do passado ou o leitor diletante, que seleciona seus livros de história com base na indicação das colunas dos mais vendidos dos cadernos de cultura? A complicar a equação, a questão da historicidade: "historiadores", "historiografia" e "audiência" não foram sempre a mesma coisa em todo lugar e em qualquer época.

Se estivéssemos trabalhando essas questões, digamos, depois da institucionalização da história na universidade no século XIX e até o começo dos anos 1990, portanto, antes da difusão da internet -, a questão da relação entre historiador/história (historiografia)/público passaria massivamente pela mídia "livro", conforme explorado nas últimas três ou quatro décadas pelos historiadores da história do livro e da leitura. ${ }^{5}$ Esse ramo da historiografia já abria para essas questões hoje aqui postas. A propósito, esse segmento ganhou seus contornos hoje conhecidos em 1957, quando em seu livro pioneiro The English common reader, Richard Altick apresentava "um mapa preliminar de um vasto território ainda virtualmente inexplorado, que aguarda os pesquisadores”. "Há espaço", dizia, "para literalmente centenas de estudos que estão apenas esboçados” (Altick, 1957, p.8-9).

Alguns historiadores avançaram no estudo das bibliotecas públicas, do comércio de livros, da imprensa de jornais e periódicos, da educação popular, da história social e econômica da autoria e edição de livros, e todos os subcampos que Altick abriu com seu estudo. ${ }^{6}$ Esse autor se esforçou para formular um campo voltado à história das editoras, dos catálogos das bibliotecas e registros de empréstimos, do nível de instrução, com vistas a determinar que livros um determinado corpo de leitores possuía ou lia. A geração seguinte da historiografia dos livros e leitores, que inclui autores como David Hall (1986), Margaret Spufford (1981), Robert Darnton (1987; 2010a; 2010b; Darnton \& Roche, 1996) e Roger 
Chartier (1998; 2003; Chartier \& Cavallo, 1998; 1999) deu um passo além dos objetivos de Altick. Essa geração posterior levantou questões como a "revolução da leitura" que se alastrou no Mundo Atlântico por volta da virada para o século XIX, quando a leitura de livros e jornais passou a ser praticamente um hábito cotidiano, não mais a leitura comunitária em voz alta, e sim individual, silenciosa e solitária. Porém, o desafio fundamental de Altick foi negligenciado num ponto central por essas novas gerações. Onde a antiga história dos livros estudava o que as pessoas liam, e a história do livro mais recente estuda como elas liam, nenhuma delas explorou realmente respostas intelectuais de massa à questão da leitura propriamente dita. Efetivamente, ninguém atacou sistematicamente a questão básica colocada por Altick: "como os textos mudam as mentes e as vidas dos leitores comuns (não profissionais)?” (Rose, 1992, p.48ss).

Num artigo já antigo, de 1992, intitulado "Rereading the English Common Reader: a preface to a history of audiences" e publicado no Journal of the History of Ideas, Jonathan Rose apontava como críticos de todas as cepas, de historiadores literários aos teóricos mais vanguardistas, tentaram discernir as mensagens ideológicas que os livros levam aos leitores. Mas ao fazê-lo se cometeu, segundo Rose, pelo menos uma das seguintes falácias em relação à resposta do leitor:

Primeira: toda literatura é política, no sentido de que ela sempre influencia a consciência do leitor;

Segunda: a influência de um dado texto é diretamente proporcional à sua circulação;

Terceira: a cultura "popular" tem uma base muito maior que a "alta" cultura e, por conseguinte, reflete com precisão as atitudes das massas;

Quarta: a "alta" cultura tende a reforçar a aceitação da ordem política e social; e Quinta: o cânone dos "grandes livros" é definido somente pelas elites sociais. Os leitores comuns ou não reconhecem esse cânone, ou então o aceitam apenas por adesão à opinião da elite. (Rose, 1992, p.48ss)

Essas cinco falácias estariam enraizadas num erro metodológico fundamental, que pode ser definido como a falácia da recepção. Ou seja, o crítico admite que o que quer que um autor coloque em seu texto - ou o que quer que seja que o crítico leia nesse texto - será sempre a mensagem que o leitor comum recebe, sem estudar as respostas de qualquer outro leitor real que não o próprio crítico. 
Efetivamente, na maior parte das vezes só se especulou sobre as reações dos hipotéticos leitores: a estética da recepção de Hans Robert Jauss (1979), o "leitor implícito" de Wolfgang Iser (1996), o "leitor informado" de Stanley Fish (1970; 1980), o "leitor qualificado" de Jonathan Culler (1982; 1997), o "leitor médio" ou "superleitor" de Michael Riffaterre (1971), o "leitor-modelo" (ou leitor-padrão), de Umberto Eco (1984) ou o "leitor-maduro", de Ronald Wardhaugh (1969). Mesmo que qualquer um desses formuladores canônicos da teoria da recepção tivesse em mente uma suposta audiência "real", essa audiência dificilmente pode ser entendida como "comum". Os leitores que interessam a Jonathan Culler, por exemplo, são todos membros da comunidade acadêmica (estudantes, críticos, professores). E o que dizer, então, do leitor do passado? Rose propõe então um terceiro nível de história da leitura: uma história das audiências, a qual "subverteria a perspectiva usual da historiografia intelectual". Tal história das audiências deverá primeiro definir um grande público, determinar sua dieta cultural, e por fim medir a resposta coletiva dessa audiência não apenas em relação a obras particulares de literatura, mas também em relação a educação formal, religião, arte e qualquer outra atividade cultural. Enquanto as histórias da recepção em geral traçavam as respostas de intelectuais profissionais (críticos literários, acadêmicos, membros do clero), uma história das audiências deverá centrar o foco no leitor comum - definido como qualquer leitor que não tenha a leitura como profissão.

Trazendo essa problemática para o campo da historiografia, é mister abrir um longo parêntese para mencionar o trabalho de quem, a meu ver, mais tem avançado nessa discussão no Brasil. Em artigo pioneiro, Fernando Nicolazzi (2010) busca "as condições de legitimidade cultural para os escritos históricos, sua razão de ser dentro da sociedade". É uma de suas hipóteses que "as condições de legitimidade para a escrita historiográfica residem, não apenas nos procedimentos escriturários de que se valem os historiadores para fundamentar seus relatos, mas também no intervalo incerto e impreciso que articula a prática da escrita com o ato de leitura" (ibidem). Resgatando George Macaulay Trevelyan, Nicollazi lembra que "falando diante de uma associação de livreiros, ele ressaltou a crise no mundo da leitura logo após os conflitos que varreram boa parte da Europa e que ainda produziriam efeitos devastadores em outras partes do planeta", e que, "num arroubo aristocrático", Trevelyan

considerou prejudicial, pelo menos neste ponto em específico, a nova formação social que se estabeleceria no pós-guerra, marcada pelo princípio de igualdade social e que, num inusitado raciocínio, fez o autor sugerir que novas e menores 
habitações seriam construídas acarretando o fim das grandes bibliotecas particulares, sendo que as públicas não conseguiriam suprir a demanda pela leitura. (Nicolazzi, 2010, p.528)

Parece imperativo contextualizar nossa problemática. Não se trata, no caso, de um "arroubo aristocrático". Trevelyan era um aristocrata, terceiro filho de Sir George Otto Trevelyan, segundo baronete, e sobrinho-neto de Thomas Babington Macaulay, cujos firmes princípios liberais whig ele expôs em obras acessíveis ao leitor comum; além disso, Trevelyan teve passagens como professor régio na University of Cambridge, diretor do Trinity College e chanceler da universidade de Durham (Hernon Jr., 1976, p.66-97).

Com o foco na questão de "como se deveria ler a história", Nicollazi problematiza outros pontos fundamentais: "as formas e condições de legitimidade do discurso produzido pelos historiadores". Trata-se de questão absolutamente legítima e pertinente, mas que deve, a meu ver, ser ampliada. “Como se deveria ler a história" ressoa quase como uma proposição normativa. Uma história das audiências, que pense a relação entre historiador e público, deverá investigar como se conhece a história: como se lê, se vê, se ouve, se vive a história. Nicolazzi está correto ao apontar para as vicissitudes da leitura, que agem sobre a escrita e determinam seu resultado, uma vez que o trabalho de leitura é perpassado pelos princípios da crítica e pela dimensão da imaginação. O problema maior, a meu ver, é que jamais teremos acesso a sequer uma amostragem mínima da recepção da historiografia pelo leitor comum, ou médio. Seu parâmetro são as sugestões de como fazer a leitura histórica oferecidas por grandes historiadores como o próprio Trevelyan, Charles-Claude Ruelle, W. von Humboldt, Augustin Thierry, Desmarest e outros autores dos séculos XVIII e XIX. ${ }^{7}$ Esses autores esperavam do leitor a mesma erudição e o mesmo senso crítico dos escritores (eruditos!) de história, o que nos permite inferir que suas reflexões sobre a pragmática da leitura se dirigiam a seus pares mesmos - um vício que em boa medida estamos praticando hoje. ${ }^{8}$

Reconheçamos que o propósito de Nicolazzi é oferecer, não um estudo sobre a leitura ou o leitor da história, mas sobre textos normativos de como, na expectativa desses historiadores aristocráticos, eruditos, a leitura da história deveria ser feita, ou seja, de como os autores de história desenhavam seus leitores ideais. A questão da leitura e do uso da história requereria, porém, a consideração do dimensionamento do público leitor vis-à-vis a população, o sistema de ensino e a alfabetização, as obras e os autores de vulgarização. A 
história, até o século XIX, não era escrita para o grande público e sim para estadistas e as classes superiores da sociedade. ${ }^{9}$

Essas são questões metodológicas relevantes da relação entre o historiador e seu público quando consideramos que o meio - a mídia - que os ligava era exclusivamente - ou ao menos massivamente - o livro, quando o historiador era o profissional treinado na pesquisa crítica e documental e o leitor era o homem educado, o leigo letrado. Mas será ainda assim? Nos dias de hoje, a equação historiador/historiografia/público tornou-se mais complexa. A "história pública" surgiu no contexto dessa amplificação dos públicos: não como exclusivamente "audiências", consumidores de história, mas, em alguma medida, como debatido a seguir, público gerador de história.

Sobre história pública não vou revolver o que todos já sabem e eu mesmo já disse em artigo publicado na História da Historiografia,${ }^{10}$ mas apenas enfatizar alguns aspectos centrais para meu argumento. Se, no começo dessa aventura, lá pelo final dos anos 1970, autores como Roy Rosenzweig, que começaram a formular esse conceito, tinham uma intenção vocal, de dar voz, de tornar autores as pessoas comuns (Rosenzweig; David, 1998), com o tempo o conceito fixou-se nas potencialidades de ação profissional dos historiadores fora do universo acadêmico. Não vou desenvolver aqui o que já trabalhei naquela ocasião, mas apenas destacar um ponto fundamental a se considerar na busca de uma definição categórica de Public History, a saber, a questão das audiências. ${ }^{11}$

O público de história se expandiu vertiginosamente nos últimos anos, para muito além do público consumidor de livros - inclusive de livros de história popular. Mas ainda resta uma longa zona cinzenta em torno do conceito de história pública. A história é "pública" porque sua produção saiu da tutela acadêmica e passou a ser largamente praticada, produzida por leigos, amadores, diletantes? Ou ela é pública pela dimensão da audiência que é capaz de atingir - e que cresceu exponencialmente nas últimas três décadas? Tanto uma coisa quanto a outra - a alteração do perfil do produtor de história e a expansão vertiginosa do seu público consumidor - se explicam em grande parte pelo surgimento de novas mídias, particularmente a internet. Esse é o segundo ponto que devemos problematizar para pensar a relação entre o historiador e o público hoje.

Há ainda outro elemento complicador, que apenas mencionarei sem oferecer aqui maior desenvolvimento, e que diz respeito às áreas de inserção da expertise dos historiadores na esfera pública, para além da atividade profissional de pesquisa e docência. Esse elemento tem a ver com as demandas sociais 
crescentes também nas três últimas décadas, relativas ao direito à memória. $\mathrm{Na}$ introdução a Historians and Social Values, ao avaliar os desafios da virada linguística lançados à historiografia nos anos 1980, Ann Rigney (2000, p.8) constatava uma "virada pragmática na reflexão teórica", que "preparou o caminho para uma reconsideração do papel social do historiador", virada que se constrói a partir da "crítica ao essencialismo" (no sentido da disciplina histórica fechada em si mesma, desconectada, por assim dizer, das questões práticas do presente). Essa tendência teórica coincidiu também com o aumento do stock de certas formas de conhecimento sobre o passado, em particular a elevação do estatuto dos discursos de memória e o valor do testemunho, não raro rotulado de "boom de memória", que vem desafiando o papel dos historiadores como os únicos intérpretes qualificados de eventos passados. Esse desafio foi particularmente vigoroso na França. Além disso, o boom nas representações de apelo popular do passado, às quais a crítica dedicou tanta atenção, também obrigou os historiadores, mesmo os mais recalcitrantes, a reavaliar sua relação com o público em geral, mesmo que em alguns casos apenas para rejeitar a necessidade de qualquer mudança de comportamento. ${ }^{12}$

\section{MeIOS E PÚBLICOS}

A história não mais se produz somente na academia, ${ }^{13}$ muito menos se veicula apenas por meio do livro impresso. As plataformas digitais subverteram as bases da produção e circulação das narrativas sobre o passado. Existe uma longa discussão, já antiga e mais técnica, sobre as potencialidades da internet para a prática historiográfica: como depósito de fontes ou ela mesma como fonte - e que tipo de problemas cada uso desses acarretaria. Por um lado, a escassez de material, dado o caráter efêmero dos websites; por outro, ao contrário, a abundância de fontes disponíveis na rede. Tudo isso exige parar para pensar na verdadeira transição de paradigmas que estamos vivendo, de uma era de escassez para uma era de abundância (Rosenzweig, 2011). Não é esse aspecto técnico, contudo, que me interessa aqui.

Outra perspectiva, mais uma vez, refere-se à ampliação massiva da audiência. A luta por incorporar todo o potencial das novas tecnologias, mas a partir das velhas práticas de pesquisa histórica, levou ao questionamento de objetivos e métodos consolidados dentro do ofício, assim como das formas narrativas. Por exemplo, a internet expandiu vertiginosamente a audiência; mas, mais que isso, a internet ampliou - a ponto de questionar - o conceito de "autoria"; assim como seu advento colocou em xeque os modelos de 
legitimação do conhecimento e autoridade. Além disso, as novas plataformas instam a rever antigos parâmetros formais de escrita, por exemplo, relativos à extensão dos trabalhos publicados em revistas acadêmicas ou anais (que antes eram ditados pelos custos de impressão). Entretanto, potencial leitor de história não é mais o especialista, nem sequer o indivíduo educado, como no século XIX e praticamente todo o século XX. Blogs e redes sociais, ${ }^{14}$ por exemplo, não aceitam o "textão". A informação e a análise devem se veicular em gotas. A capacidade e a disponibilidade de leitura hoje contam-se em dígitos.

Não podemos mensurar com precisão o impacto que o advento da internet significou para a cultura histórica em geral, e para a relação historiador-público em particular. Ela virou do avesso o próprio conceito de "história pública". Um artigo recente de Meg Foster, "Online and Plugged in?: Public History and Historians in the digital age" (2014), na Public History Review, levanta questões pertinentes para o nosso debate.

Segundo Foster, a Web 2.0 afeta a forma como as pessoas interagem umas com as outras, incluindo o modo como os historiadores públicos e as pessoas comuns se conectam com a história. Fóruns online, blogs, dispositivos portáteis, aplicativos celulares, tablets, mídias sociais e uma incontável gama de plataformas digitais têm facilitado um maior grau de "envolvimento do usuário" (user engagement), em que qualquer pessoa com acesso à web é capaz de contribuir para a compreensão sobre o passado.

O ensaio de Foster analisa justamente a relação complexa e poderosa entre a internet e história pública. Ele explora como a história pública está sendo experimentada e praticada em um mundo digital onde tanto os historiadores públicos como os leigos atuam na produção e difusão do conhecimento histórico por meio da world wide web. A Web 2.0 é um terreno dinâmico que oferece oportunidades e desafios para a criação da história. Se, por um lado, ela pode potencialmente ser um meio indutor de produção de uma história ao alcance de todos, por isso em tese mais democrática e mais aberta, a internet simultaneamente apresenta questões e desafios novos, por exemplo, sobre controle de acesso (salvaguarda: gatekeeping) e autoridade (quem tem habilidades técnicas, formação necessária para fazer sentido do passado como história). Do mesmo modo, a Web 2.0 tende a alterar o estatuto da história pública. $\mathrm{O}$ antigo status de historiadores como os produtores, e de "leigos" como o público consumidor da história, é agora posto em questão. Esse é um aspecto central: mais e mais pessoas comuns estão usando tecnologias online para acionar o passado (e também falar de história), e os historiadores devem estar alertas a essas mudanças. Tal constatação pode ser comprovada pela onda de trabalhos 
históricos que jorram do ciberespaço. Os autores desses trabalhos vão desde intelectuais até administradores de empresas e motoristas de ambulância, dispersos por todo o globo (Ufberg, 2014).

A rígida divisão a que estamos familiarizados entre produtores (homens e mulheres treinados na universidade nos fundamentos da história como ciência, no manejo de fontes e do método crítico) e consumidores de conhecimento sobre o passado se destina em alguma medida a salvaguardar a autonomia dos historiadores profissionais. O processo de ampliação vertiginosa de protagonistas e meios de circulação da história, porém, coloca em xeque aquela divisão. O discurso da autoridade não cola bem no mundo real - muito menos no mundo virtual. Além disso, a web parece configurar-se numa espécie de "esfera pública" que dispensa qualquer "validação" formal ou atestado de competência para uma interpretação particular do passado. Nesse ambiente imune ao discurso da autoridade, parece crucial que os historiadores busquem não apenas o avanço do conhecimento, mas também entender como esse conhecimento vem sendo testado e negociado.

Seria um erro supor, no entanto, que o impacto da Web 2.0 seja apenas ao dispersar seu poder produtivo. Há também convergência: as pessoas estão se unindo e trabalhando para produzir um tipo de história diferente. Esse novo mundo online da história pública não carece de nenhuma das nuances e do dinamismo que têm caracterizado o campo desde a sua criação. Questões de participação, audiência e exposição são tão complexos quanto sempre foram, mas a plataforma digital os potencializa exponencialmente.

Ainda segundo Foster, a noção de que o público pode e deve ser envolvido na criação do passado não é nova. Em 1990, o termo "autoridade compartilhada" foi cunhado pelo historiador oral Michael Frisch e usado para descrever uma forma ideal de fazer história. Os historiadores não simplesmente divulgam o conhecimento para o público, mas devem trabalhar em conjunto com as pessoas comuns. O passado seria reconhecido como o terreno social em constante mudança, e os historiadores e o público deveriam cooperar e trocar ideias de modo a que sua expertise pudesse satisfazer as necessidades, desejos e conhecimento cultural do outro (Foster, 2014, p.4; Frisch, 1990). O que mudou, e o que torna mais imprevisíveis as possibilidades futuras para a história pública, é como as novas tecnologias têm acelerado essa tendência. Diz Foster:

Os historiadores são forçados a confrontar questões de autoridade partilhada e participação do público, porque o passado pode ser - e está sendo - criado, acessado e resgatado à revelia deles nas mídias digitais. As pessoas comuns têm acesso 
a fontes primárias por meio de bases de dados e da digitalização de material histórico depositado na rede. Eles têm plataformas virtuais como Twitter e blogs e são capazes de criar páginas web para compartilhar suas ideias. (Foster, 2014, p.17)

A registrar que também essa ideia de democratização da produção histórica não é nova. Ao menos, ela já havia sido vislumbrada em potência no começo do século XX por Carl Becker, em seu clássico discurso presidencial na American Historical Association, Everyman his own historian. Para Becker, no futuro, todo homem comum seria historiador de si mesmo (Becker, 2013). O escopo dessas novas e "democráticas" produções da história, nas quais cada pessoa é seu próprio historiador, é claramente ilustrado pela autora ao se olhar para a conta @historyinpics no Twitter. Esse site compartilha imagens do passado postando uma nova imagem a cada duas horas, em particular fotos de celebridades e eventos famosos. ${ }^{15}$ Semelhante a essa iniciativa, há dezenas de páginas no Facebook sobre a história (sobretudo visual) de cidades brasileiras. ${ }^{16}$

A crítica por parte dos historiadores a empreendimentos desse tipo gira em torno da falta de contextualização histórica e crítica documental. Não obstante, seu sucesso é estrondoso. ${ }^{17}$ Em edição recente da Public History Review que examinou "New Directions in Public History", o historiador americano James Gardner chega a sugerir que os historiadores estariam sob a ameaça da "confiança radical" que concedem ao público. Confiança radical que não se confundiria com a "autoridade partilhada" imaginada por Michael Frisch, mas que implicaria os historiadores desistirem completamente de seu poder e influência, outorgando ao público "determinar o futuro da história pública". Como Gardner percebe a questão, "Não há meio caminho em confiança radical. Se nós [historiadores] mediarmos ou se filtrarmos a opinião não editada e sem censura, então estaremos a violar essa confiança”. No futuro sombrio projetado por Gardner, os historiadores e a "história real" estão fadados a perecer; pois, se o público detiver toda a autoridade, então não haverá espaço para os historiadores participarem na construção do passado. Numa exorbitação da ideia de "passado prático" em detrimento do "passado histórico", Gardner prevê que o público vai usar o passado para reforçar as suas próprias expectativas e preconceitos, e a "história" vai culminar no rearranjo dos fatos para os propósitos presentes, perdendo-se o verdadeiro significado histórico. ${ }^{18}$

Os historiadores públicos são particularmente interessados na interação entre o passado e o presente. Eles sempre tiveram o público como fator determinante de sua própria atuação. A ideia de que e de quem constitui "o público", 
porém, veio se alterando substancialmente desde a própria emergência da história pública nos anos 1970. A Web 2.0 é mais um fator de impacto na alteração do conceito de público. Ligada a essa questão está outra essencial aqui: a questão da construção de uma cultura histórica para além dos muros da academia. Cada vez mais pessoas interessadas em fazer sentido do passado voltam-se à história como espaço de experiência para guiar sua ação ou para utilizar esse conhecimento como arma política no presente. Esse tema introduz o terceiro ponto de meu argumento, que deve servir como tentativa de amarração, e que se refere à questão da responsabilidade do historiador.

\section{DESAFIOS À HISTÓRIA DISCIPLINAR}

Essa é uma questão de fundo, mais ampla, que acomete a todos e todas que se dirijam ao público para falar de/sobre história, e que pode se desdobrar assim: dada toda essa complexidade que envolve a relação do(a) profissional historiador(a) com o público, quais são as responsabilidades do acadêmico e da acadêmica de história hoje? Como lidamos com essas responsabilidades? Como nós monitoramos e referendamos ou não a atuação daqueles dentre nós para quem a sociedade confiou salas de aula, meios de comunicação, seus museus e sítios históricos, arquivos e outras instituições culturais? Ou como tratamos com a presença, atuação e o trabalho daqueles que, independentemente de treinamento profissional, de formação acadêmica, falam de história ao grande público por quaisquer meios?

Ao longo das últimas décadas, testemunhamos mudanças dramáticas nos modos como se define, se escreve e se consome história. O historiador hoje vive a tensão de, por um lado, diante da hiperespecialização, escrever apenas para seus pares; por outro, ter a saudável ambição de falar para públicos amplos. Nesse terreno, vê-se impelido a competir com produtores leigos de conhecimento histórico por uma ampla e heterogênea audiência. Queremos falar para qualquer pessoa, de qualquer extração, que queira saber sobre o passado e sua relação com o tempo presente. Uma vantagem disso é a clara democratização da história como disciplina fundadora de identidade, que nos ajuda a discernir quem somos, onde estamos e para onde podemos ir. ${ }^{19}$ Essa expansão democrática da audiência fez explodir o número de pessoas que podem ver a si mesmas, suas famílias, suas comunidades étnicas, sexuais, religiosas, de vizinhança etc. nas inúmeras narrativas históricas que se veiculam no caleidoscópio atordoante disponível de textos históricos, filmes, exibições em museus, minisséries televisivas, websites, lugares de memória, ebooks, blogs, arquivos 
eletrônicos e toda parafernália online disponível, inclusive de e-commerce. Para ser justo, o velho padrão formal, focado nos diversos modelos de narrativa histórica, ainda impera por todo lado, principalmente na academia, mas também em outras instituições culturais. Porém, como argumentei acima, hoje a vocalização da história deixou de ser prerrogativa do historiador formado, profissional. Jornalistas e antiquários, genealogistas e ativistas sociais, estudantes secundaristas, ou mesmo o velho médico, advogado, jornalista ou professor aposentado diletantes juntaram-se ao coro dos cronistas da "história viva". A presença desses historiadores acidentais ou incidentais não é em si algo ruim. Ela acaba enriquecendo o diálogo sobre quem somos enquanto cultura e povo, e desafia a nós, historiadores profissionais, a praticarmos nosso ofício de maneira viva e engajada, como sói ser o trabalho desses novos contadores de histórias que têm cativado a atenção do grande público. Mas vale lembrar, também, o caso de pessoas com algum estoque de conhecimento histórico manejando esse conhecimento na prática política cotidiana, à esquerda e à direita do espectro político.

Toda essa expansão do diálogo, porém, não se faz sem custos. A disponibilidade de uma ampla rede de difusão de conhecimento histórico, como os canais e livros populares de história, biografias, exposições, websites, documentários, filmes e séries de fundo histórico veiculados em televisão e cinema, para nomear só alguns, muitas vezes implica que qualquer um detém autoridade e é responsável - o que significa, de modo inverso, que ninguém é responsável e detém a autoridade sobre o conhecimento histórico. O sucesso de mercado, as tiragens, as cifras de venda e o reconhecimento do público (consumidor) passam a ser as bitolas com que se mede a qualidade do conhecimento, em detrimento das tradicionais instâncias de legitimação do saber acadêmico como as conhecíamos desde a estruturação da moderna universidade: as bancas, os peer reviewers das revistas e editoras, os congressos, consultores ad hoc e assim por diante. A questão que se coloca é: será que nós, historiadores treinados para pesquisar, escrever e ensinar história perdemos controle, credibilidade e autoridade sobre essas práticas? Quais são o papel e as responsabilidades dos historiadores acadêmicos hoje? ${ }^{20}$

Essa questão da autoridade sobre o passado, decorrente da relação entre o historiador e o público, é candente hoje e carrega em si um dos maiores desafios aos historiadores profissionais desde o surgimento da história como disciplina acadêmica. Ou nós a encaramos e propomos respostas, ou aceitamos a provocação de Wulf Kansteiner (1996) que já tem duas décadas, da existência de uma consciência crescente da insignificância social e política da produção 
histórica acadêmica nas sociedades ocidentais contemporâneas. Enfim, que a imensa demanda social por história no mundo atual teria como objeto não a história-conhecimento, a história como ciência, construída por historiadores acadêmicos, mas as narrativas sobre o passado de caráter popular. Se for esse o caso, ganha pleno sentido o lamento da historiadora Marixa Lasso, nas exéquias da profissão de historiador.

\section{REFERÊNCIAS}

ABREU, Márcia. Da maneira correta de ler: leituras das Belas Letras no Brasil colonial. In: (Org.) Leitura, História e História da Leitura. Campinas: Mercado de Letras; ALB; Fapesp, 2000. p.213-234.

ALMEIDA, Juniele R. de; ROVAI, Marta G. de O. (Org.) Introdução à história pública. São Paulo: Letra e Voz, 2011.

ALTICK, Richard. The English Common Reader. Chicago: University of Chicago Press, 1957.

APPLEBY. Joyce; HUNT, Lynn; JACOB, Margaret. Telling the Truth About History. London: Norton, 1994.

ARAÚJO, Valdei L. Historiografia, nação e os regimes de autonomia na vida letrada no Império do Brasil. Varia Historia, Belo Horizonte, v.31, n.56, p.365-400, maio/ ago. 2015.

BECKER, Carl. O homem comum é seu próprio historiador. In: MALERBA, Jurandir. Lições de história: da história científica à crítica da razão metódica. Rio de Janeiro: Ed. FGV; Porto Alegre: Ed. PUC-RS, 2013.

CHARTIER, Roger. A aventura do livro: do leitor ao navegador. São Paulo: Ed. Unesp; Imprensa Oficial, 1998.

. Leituras e leitores na França do Antigo Regime. São Paulo: Ed. Unesp, 2003. .; CAVALLO, Guglielmo (Org.) História da leitura no mundo ocidental 1. São Paulo: Ática, 1998.

.; CAVALLO, Guglielmo (Org.) História da leitura no mundo ocidental 2. São Paulo: Ática, 1999.

COCKIN, Georg. History's moral turn. Journal of history of ideas, v.69, n.2, p.293-315, 2008.

CULLER, Jonathan. On Deconstruction: Theory and Criticism after Structuralism. Ithaca, NY: Cornell University Press, 1982.

. Literary Theory: A Very Short Introduction. Oxford: Oxford University Press, 1997. 
DAINES III, J. G.; NIMER, Cory L. Introduction. The Interactive Archivist, 18 May 2009. Disponível em: http://interactivearchivist.archivists.org/\#footnote13; Acesso em: 12 maio 2016.

DARNTON, Robert. O beijo de Lamourette: mídia, cultura e revolução. São Paulo: Companhia das Letras, 2010a.

. Boemia literária e Revolução: o submundo das letras no Antigo Regime. São Paulo: Companhia das Letras, 1987.

A questão dos livros: passado, presente e futuro. São Paulo: Companhia das Letras, 2010b.

.; ROCHE, Daniel. A revolução impressa: a imprensa na França, 1775-1800. São Paulo: Edusp, 1996.

ECO, Umberto. The Role of the Reader: Explorations in the Semiotics of Texts. Bloomington, IN: Indiana University Press, 1984.

FERREIRA, Giovandro M. Do círculo semiológico ao círculo hermenêutico: contribuições de Paul Ricoeur à análise do discurso. Interface, Vitória: Ufes, p.81-94, 1999.

FISH, Stanley E. Literature in the reader: Affective Stylistics. New Literary History, Baltimore, MD: Johns Hopkins University Press, v.2, n.1, p.123-162, 1970.

. Is there a text in the class? The authority of interpretative communities. Cambridge, MA: Harvard University Press, 1980.

FOSTER, Meg. Online and Plugged in? Public History and Historians in the digital age. Public History Review, v.21, p.1-19, 2014.

FREIXO, André de L. Legados da disciplina histórica: experiências na fronteira entre consensos e horizontes. Topoi, Rio de Janeiro, v.16, n.31, p.707-716, jul./dez. 2015.

FRISCH, Michael. From a Shared Authority to the Digital Kitchen, and Back. In: ADAIR, Bill; FILENE, Benjamin; KOLOSKI, Laura (Ed.) Letting Go? Sharing Historical Authority in a User-Generated World. Philadelphia, PA: The Pew Center for Arts and Heritage, 2011. p.126-137.

. A Shared Authority: Essays on the Craft and Meaning of Oral and Public History. New York: State University of New York Press, 1990.

FUCHS, Eckhardt. Conceptions of Scientific History in the Nineteenth-Century West. In: IGGERS, Georg; WANG, Edward (Org.) Turning points in Historiography: A cross cultural perspective. Rochester, NY: The University of Rochester Press, 2002. p.147-162.

GARDNER, James B. Trust, Risk and Public History: A View from the United States. Public History Review, v.17, p.52-61, 2010.

HALL, David D. The History of the Book: New Questions? New Answers? The Journal of Library History, v.21, n.1, p.27-38, 1986. 
HERNON, Jr.; Joseph M. The Last Whig Historian and Consensus History: George Macaulay Trevelyan, 1876-1962. The American Historical Review, v.81, n.1, p.66-97, 1976.

ISER, Wolfgang. O Ato da Leitura: uma teoria do efeito estético. São Paulo: Ed. 34, 1996.

JAUSS, Hans R. A história da literatura como provocação à teoria literária. São Paulo: Ática, 1979.

KANSTEINER, Wulf. Searching for an Audience: The Historical Profession in the Media Age - A Comment on Arthur Marwick and Hayden White. Journal of Contemporary History, v.31, n.1, p.215-219, jan. 1996.

LAPSANSKY, Emma. An honor system for historians? Journal of American History, v.90, n.4, p.1351-1356, 2004.

LASSO, Marixa. ¿Por qué y para quién escribimos? Presentación para la mesa redonda: ¿Qué Implicó ser Historiador en el Pasado? In: APORTES AL PENSAMIENTO HISTÓRICO (Workshop). In Memoriam: Jaime Jamarilo Uribe. Universidad Nacional da Colombia, 28-29 abr. 2016, Bogotá. Publicado em: El Espectador, Bogotá, 30 maio 2016. Disponível em: http://www.elespectador.com/noticias/cultura/y-quien-escribimos-los-historiadores-articulo-635072; Acesso em: 31 maio 2016.

MALERBA, Jurandir (Org.) Acadêmicos na berlinda ou como cada um escreve a história: uma reflexão sobre o embate entre historiadores acadêmicos e não acadêmicos no Brasil à luz dos debates sobre Public History. História da Historiografia, Ouro Preto, n.15, p.27-50, ago. 2014.

História é narrativa: a ciência e a arte da escrita histórica. Petrópolis: Vozes, 2016.

(Org.) Lições de História: o caminho da ciência no longo século XIX. Rio de Janeiro: Ed. FGV; Porto Alegre: Ed. PUC-RS, 2010.

. (Org.) Lições de História: da história científica à crítica da razão metódica no limiar do século XX. Rio de Janeiro: Ed. FGV; Porto Alegre: Ed. PUC-RS, 2013.

MARTINS, Estevão de R. Conhecimento histórico e historiografia brasileira contemporânea. Revista Portuguesa de História, v.42, p.197-219, 2011.

MAUAD, Ana M.; ALMEIDA, Juniele R.; SANTHIAGO, Ricardo (Org.) História pública no Brasil: sentidos e itinerários. São Paulo: Letra e Voz, 2016.

MEGUILL, Allan. Literatura e História. In: MALERBA, Jurandir (Org.) História \& narrativa: a ciência e a arte da escrita histórica. Petrópolis: Vozes, 2016.

NAPOLITANO, Marcos. Historiografia, memória e história do regime militar brasileiro. Revista de Sociologia e Política, Curitiba, n.23, p.193-196, nov. 2004.

NICOLAZZI, Fernando. Como se deve ler a história? Leitura e legitimação na historiografia moderna. Varia Historia, Belo Horizonte, v.26, n.44, p.523-545, jul./dez. 2010. 
NICOLAZZI, Fernando. O historiador enquanto leitor: história da historiografia e leitura da história. História da Historiografia, Ouro Preto, n.13, p.63-77, 2013.

PEREIRA, Mateus H. de F. Nova direita? Guerras de memória em tempos de Comissão da Verdade (2012-2014). Varia Historia, Belo Horizonte, v.31, n.57, p.863-902, set./ dez. 2015.

REIS, José C. Tempo, História e Compreensão Narrativa em Paul Ricoeur. Locus, Juiz de Fora, v.12, n.1, p.17-40, 2006.

RIFFATERRE, Michael. Essais de stylistique structurale. Paris: Flammarion, 1971.

RIGNEY, Ann. Introduction: Values, Responsibilities, History. In: RIGNEY, Ann; LEERSSEN, Joep (Ed.) Historians and Social Values. Amsterdam: Amsterdam University Press, 2000.

ROSE, Jonathan. Rereading the English Common Reader: a preface to a history of audiences. Journal of the History of Ideas, v.53, n.1, p.47-70, 1992.

ROSENZWEIG, Roy. Scarcity or Abundance? Preserving the past in a digital era. In: Clio Wired: The Future of the Past in the Digital Age. New York: Columbia University Press, 2011.

.; DAVID, Helen T. The Presence of the Past: Popular Uses of History in American Life. New York: Columbia University Press, 1998.

RÜSEN, Jörn. Teoria da História: uma teoria da história como ciência. Curitiba: Ed. UFPR, 2015.

SCHAPOCHNIK, Nelson. Contextos de leitura no Rio de Janeiro do século XIX: salões, gabinetes literários e bibliotecas. In: BRESCIANI, Stella (Org.) Imagens da cidade, séculos XIX e XX. São Paulo: Marco Zero, 1994. p.147-162.

.; ABREU, Marcia (Org.) Cultura letrada: objetos e práticas. Campinas: Mercado de Letras, 2005.

SPUFFORD, Margaret. Small Books and Pleasant Histories: Popular fiction and its readership in seventeenth-century England. London: Methuen, 1981.

STEINHAUER, Jason. @HistoryinPics Brings History to the Public. So What's the Problem? Part 1. History@Work Blog, 18 February 2014. Disponível em: http:// ncph.org/history-at-work/historyinpics-part-1/; Acesso em: 18 abr. 2016.

. @HistoryinPics Brings History to the Public. So What's the Problem? Part 2. History@Work Blog, 19 February 2014. Disponível em: http://ncph.org/history-at-work/historyinpics-part-2/; Acesso em: 20 abr. 2016.

STEVENS, Mary. Public Policy and the Public Historian: The Changing Place of Historians in Public Life in France and the UK. The Public Historian, v.32, n.3, p.120138, Aug. 2010.

TODOROV, Tzvetan; GOLSAN, Lucy. The morality of the historian. South Central Review, The South Central Modern Language Association/Johns Hopkins, v.15, n.3/4, p.6-15, 1998. 
TURIN, Rodrigo. História da historiografia e memória disciplinar: reflexões sobre um gênero. História da Historiografia, Ouro Preto, n.13, p.78-95, 2013.

UFBERG, Max. Regular Guy from Boston Decides to Map the City's Entire History. Wired, 2 January 2014. Disponível em: http://www.wired.com/2014/10/ed-mccarthy-boston-history-mapper; Acesso em: 10 maio 2016.

VARELLA, Flávia F.; MOLLO, Helena M.; MATA, Sérgio R. da; ARAUJO, Valdei L. de (Org.) A dinâmica do historicismo: revisitando a historiografia moderna. Belo Horizonte: Argvmentvm, 2008.

VILLALTA, Luiz C. A história do livro e da leitura no Brasil Colonial: balanço historiográfico e proposição de uma pesquisa sobre o Romance. Convergência Lusíada, Rio de Janeiro: Real Gabinete Português de Leitura, v.21, p.165-185, 2005.

. O que se fala e o que se lê: língua, instrução e leitura. In: NOVAIS, Fernando A. (Coord.); SOUZA, Laura de M. (Org.) História da vida privada no Brasil, 1: cotidiano e vida privada na América portuguesa. São Paulo: Companhia das Letras, 1997. p.332-385.

WARDHAUGH, Ronald. Reading: A Linguistic Perspective. New York: Harcourt, Brace \& World, 1969.

WHITE, Hayden; DIMENDBERG, Ed. The Practical Past. Evanston, IL: Northwestern University Press, 2014. Project MUSE. Web. 17 Jun. 2016. Disponível em: https:// muse.jhu.edu/.

\section{NOTAS}

${ }^{1}$ Este artigo teve uma primeira versão elaborada para apresentação na mesa-redonda "Os públicos da história: currículos, formação e ensino de História em debate”, no 9 Seminário Nacional de História da Historiografia (Vitória, 24 maio 2015); depois refeita para $2^{\text {nd }}$ INTH network conference "The Practical Past: on the advantages and disadvantages of history for life" (ago. 2016). Agradeço aos organizadores e participantes desses eventos, a Valdei Lopes Araújo, Fernando Nicolazzi e Matheus Pereira e aos três consultores ad hoc acionados pela RBH pelas generosas leituras e sugestões. Os equívocos remanescentes são de minha responsabilidade.

${ }^{2}$ Doutor em História pela Universidade de São Paulo (USP). Professor Titular da Universidade Federal do Rio Grande do Sul (UFRGS) e Pesquisador CNPq.

${ }^{3}$ Cf. MALERBA, 2010 e 2013, e a sugestiva resenha de André de Lemos Freixo (FREIXO, 2015, p.707-716). Também FUCHS, 2002; VARELLA et al., 2008.

${ }^{4}$ De acordo com a proposta clássica de Ricoeur, as operações conduzidas pela semiótica textual tornam-se uma parte do círculo hermenêutico na articulação das três mimesis. $\mathrm{O}$ círculo semiológico torna-se uma das mimesis (II) que se encontra situada entre as outras duas: a mimesis I ou a pré-figuração e a mimesis III ou a refiguração. Cf. REIS, 2006, p.1740; FERREIRA, 1999, p.81-94. 
${ }^{5}$ Consideramos a existência de outros circuitos produtores de conhecimento histórico (como os institutos históricos e os autodidatas) e formas diversas de produção e disseminação de consciência histórica, num sentido mais amplo que a historiografia. A literatura, o teatro ou o ensino escolar, pelo menos desde o século XIX, somando-se o rádio, a televisão e o cinema, no século XX, assim o atestam. Na impossibilidade lógica de trilhar todos os caminhos ao mesmo tempo, nosso foco neste artigo há de ser mais restrito, com ênfase na historiografia. A preponderância da mídia livro e do historiador erudito apresenta nuances; porém, quando pensamos em termos de produção e circulação do conhecimento histórico no período em tela, não há como diminuir a regra ante as exceções.

${ }^{6}$ Expoentes da historiografia do livro e da leitura no Brasil incluem VILLALTA, 1997 e 2005; SCHAPOCHNIK, 1994; SCHAPOCHNIK; ABREU, 2005; ABREU, 2000.

${ }^{7}$ Em outro belíssimo e erudito ensaio, Nicollazi perscruta as considerações a respeito da leitura da história feitas pelo historiador e antiquário francês Claude-François Menestrier em sua obra Les divers caracteres des ouvrages historiques, publicada em 1694. Cf. NICOLAZZI, 2013, p.63-77.

8 “A erudição que Thierry defende, portanto, é a erudição da leitura sobre os textos de história, do trabalho erudito que o leitor deve dirigir aos escritos dos historiadores ou daqueles que se ocuparam de escrever sobre o passado". Cf. NICOLAZZI, 2010, p.532.

${ }^{9}$ A situação se torna mais complexa a partir do século XX. Pari passu à construção do modelo disciplinar, institucionalizado e vinculado ao projeto de consolidação da nação-Estado, novas modalidades de escrita de viés mais popular, visando suprir uma nascente demanda social por história, começam a ser encetadas. $\mathrm{O}$ fenômeno é perceptível também no Brasil. Cf. ARAÚJO, 2015.

${ }^{10}$ Cf. MALERBA, 2014, p.27-50. Vale menção o dossiê da revista Estudos Históricos sobre o tema (v.27, n.54, 2014) e os esforços da Rede Brasileira de História Pública (http://historiapublica.com.br/), que, entre outros empreendimentos, promoveu o I e o II Simpósio Internacional de História Pública (USP, 2012 e UFF, 2014) e algumas publicações de referência. Cf. ALMEIDA; ROVAI, 2011; também MAUAD; ALMEIDA; SANTHIAGO, 2016.

${ }^{11}$ A questão da formação dos praticantes da história pública eu abordei no texto acima referido, destacando a diferença essencial entre o que ocorre em todos os lugares em que se pratica a história pública, como nos Estados Unidos, Inglaterra ou Austrália, onde os public historians são profissionais treinados na universidade, e no Brasil, onde a presença de leigos nessa atividade é a regra.

${ }^{12}$ Cf. STEVENS, 2010, especificamente p.121-122. O boom de memória no Brasil teve grande impulso com os estudos sobre a ditadura civil-militar. Cf. PEREIRA, 2015; NAPOLITANO, 2004; MARTINS, 2011. Uma reflexão instigante sobre o gênero em TURIN, 2013.

${ }^{13}$ Mais uma vez, entendemos que sempre se produziu e ainda se produz historiografia fora dos circuitos acadêmicos. Chamamos a atenção aqui para o fato de que aquela história com instâncias institucionais de reconhecimento e legitimação, que produziu a "história 
como ciência" ao longo de boa parte dos séculos XIX e XX, é essa historiografia que hoje perde espaço de legitimação, principalmente ante o público. É disso que se trata aqui.

${ }^{14}$ Cf. http://www.historianet.com.br/home/; http://www.sohistoria.com.br/; http:// historiadomundo.uol.com.br/; http://www.historiadobrasil.net/; https://historiablog.org/; http://www.historiadigital.org/; http://historiahoje.com/. O Café História é um marco no Brasil no que tange à inserção da história no universo digital: http://cafehistoria.ning. com/; Acessos em: 20 jun. 2016.

15 ‘@HistoryInPics', Historyinpics, twitter page; Acesso em: 23 abr. 2014 via https://twitter. com/HistoryInPics; Jason Steinhauer, '@HistoryinPics Brings History to the Public. So What's the Problem? Part 1,' History@Work Blog,18 February 2014; Acesso em: 18 abr. 2016 via: http://ncph.org/history-at-work/historyinpics-part-1/; Jason teinhauer, '@HistoryinPics Brings History to the Public. So What's the Problem? Part 2', History@Work Blog, 19 February 2014; Acesso em: 20 abr. 2016 via: http://ncph.org/history-at-work/historyinpicspart-2/.

16 Cf. https://www.facebook.com/groups/bebedouroemfoco/?fref=ts; https://www. facebook.com/groups/LorenaEmFotosAntigas/

https://www.facebook.com/groups/memoriaspaulistanas/?fref=ts; https://www.facebook. com/memoriapaulistana/?fref=ts;

https://www.facebook.com/quemteviuquemtv/?fref=ts;

https://www.facebook.com/rio.antigo.5?fref=ts; Acessos em: 17 maio 2016.

${ }^{17}$ Há vários empreendimentos genéricos, em diversos meios: http://historyinpictures. tumblr.com/; https://twitter.com/historyinpix; https://twitter.com/historyinpics?lang=pt; https://www.instagram.com/historyphotographed/; https://www.facebook.com/ historyallday/; Acessos em: 17 maio 2016. Críticas também existem, como a da blogueira Rebecca Onion: "Snapshots of History. Wildly popular accounts like @HistoryInPics are bad for history, bad for Twitter, and bad for you". Disponível em: http://www.slate.com/ articles/life/history/2014/02/_historyinpics_historicalpics_history_pics_why_the_wildly_ popular_twitter.html; Acesso em: 18 maio 2016.

${ }^{18}$ GARDNER, 2010, p.53. Esse autor é trazido à discussão por FOSTER, 2014, p.5. Sobre a ideia de practical past, cf. WHITE; DIMENDBERG, 2014; também APPLEBY; HUNT; JACOB, 1994.

${ }^{19}$ Sempre referenciais as reflexões de Rüsen, retomadas em seu livro de maturidade (RÜSEN, 2015).

${ }^{20}$ Não são poucos aqueles que se têm dedicado a pensar o problema. Cf. LAPSANSKY, 2004; FRISCH, 2011; TODOROV; GOLSAN, 1998; COCKIN, 2008.

Artigo recebido em 5 de julho de 2016. Aprovado em 24 de outubro de 2016. 